\title{
MRI of a Poet's Brain
}

Vernon Rowe, MD

vrowe@neurokc.com

In this image

of your brain

I see each curve

in the corpus callosum,

curlicues of gyri,

folding of fissures,

sinuous sulci,

mammillary bodies,

arcuate fasciculus,

angular gyrus,

tracts and nuclei,

BOLD blood flow,

eyes and ears,

tongue and pharynx--

but not a single

syllable of

one

tiny

poem.

This poem was included in Sea Creatures, 1995, by Vernon Rowe,

M.D. 